\title{
GASTO PUBLICO Y CRECIMIENTO ECONOMICO EN LA RESTAURACION (1874-1923) *
}

\author{
ANTONIO CUBEL MONTESINOS \\ Universidad de Valencia
}

\section{RESUMEN}

Las aportaciones más recientes sobre la importancia del Eetado en el crecimiento de la economia española durante la Restauración han serialado la reducida relevancia que el gasto público tenia en la determinacion de la renta nacional En este articulo se discute tal afirmación llegando a la conclusión de que tal afirmación infravalorabe la verdadera importancia del presupuesto, principalmente en relación con la producción industrial. Mediante la utilización de métodos econométricos se analiza la relevancia de las variaciones en los diferentes componentes del presupuesto en la variación de la producción nacional.

\section{SUMMARY}

The most recent contributions on the relevance of the State in the growth of the Spanish economy during the Restoration have remarked the limited significance that public expenditure had in the determination of the national income. This article discuseses that opinion concluding that the actual importance of the budget, especially rela. ted with industrial output, was underrated. We use econometric methods to capture the consequences of budget different components variations on national output.

* Una primera versión de este trabajo fue presentada en el Encuentro de Historia Económica celebrado en Valencia en octubre de 1991. Agradezco los comentarios y el interés que allí demostraron Francisco Comin y Pedro Fraile.

Su realización no hubiera sido posible sin la ayuda de Javier Andrés y Ezequiel Uriel, miembros del Departamento de Análisis Económico de la Universidad de Valencia, y de mis compañe. ros del Seminario de Historia Económica, especialmente Jordi Palafox. La realización de este trabajo, que forma parte de mi tesis doctoral, fue posible gracias a una ayuda para la realización de tesis doctorales del Banco de España. 
Uno de los temas de investigación más fructifero e interesante que tiene planteado la historia económica en nuestro pais es la explicación del atraso español. Y, más en concreto, el de la importancia del periodo 1860-1913. Tras un periodo de aproximadamente 30 años, los que arrancan en 1830 , en el cual las tasas de crecimiento de la producción industrial fueron similares a las del resto de Europa (Gran Bretaña, Francia, Alemania, Austria-Hungria, tuvieron tasas comprendidas entre el 2,7 y el 2,9 por 100 , mientras las españolas eran del 2,6 por 100 en las estimaciones más bajas y sustancialmente superiores -4,7 por 100 - en las más elevadas), el último tercio del siglo representó una ralentización del crecimiento y una ampliación de la distancia que separaba España de las principales naciones europeas ${ }^{1}$.

Las explicaciones sobre el retardo han sido diversas: el atraso agrario ${ }^{2}$, la falta de competitividad de la industria nacional ${ }^{3}$ o la falta de dinamismo del sector exterior ${ }^{4}$. Entre los diferentes factores que pudieron haber contribuido a conformar esa situación de atraso quiero destacar uno que ya ha sido señalado en anteriores ocasiones ': el Estado. Su actuación ha sido señalada, de forma relevante, como causa del freno al crecimiento durante la Restauración. Dos explicaciones han sido aportadas: la creación de obstáculos al funcionamiento eficiente del mecanismo de mercado y la reducida influencia que el presupuesto tuvo en la generación de la demanda interna.

La primera interpretación surge de la modificación de objetivos de la politica económica que se apunta en 1874 , a partir de la derogación de la reforma arancelaria de Laureano Figuerola, y se desarrolla plenamente a partir de 1891, en la que ha sido llamada «vía nacionalista del capitalismo español 6. Este fue un proceso de reducción de las relaciones comerciales con el exterior, básicamente por la imposición de elevados aranceles, que en el interior dio como resultado la articulación de una política económica con tres constantes básicas: proteccionismo, nacionalismo económico e intervencionismo estatal ?.

1 La tasa de crecimiento española fue del 2,2 por 100, similar a la de Francia (2,4), Gran Bretaña (2,2) e Italia (2,6), pero inferior a la de Alemania (4), Austria-Hungria (3), Estados Unidos $(4,9)$, Rusia $(4,2)$, Suecia $(5,2)$. Les estimaciones proceden de Carreras. El valor más bajo para el periodo 1830-1860, en Prados de la Escosura (1988).

2 Nadal (1975), p. 227.

3 Fraile (1985b), pp. 100-104; Prados (1988), cap 4.

4 Fraile (1985a), pp. 244-246.

, Nadal (1975), p. 28.

- Muñoz, Roldán y Serrano (1978).

7 Muñoz, Roldän y Serrano (1978), pp. 57-70. 
Su consecuencia fue la separación de la estructura de costes de las industrias españolas de sus competidoras europeas, lo que provocó la aparición de dificultades para encontrar mercados exteriores en unos momentos en los cuales se estaba produciendo, a nivel internacional, un cambio en las ventajas comparativas que iba a provocar la consiguiente reestructuración productiva, al que España no consiguió adaptarse debido a la orientación de su politica económi$\mathrm{Ca}^{8}$. Además, el alejamiento del mercado exterior provocó una elevación de los precios interiores que impidió la liberación de capacidad de compra, la cual, en caso contrario, hubiera podido contribuir a la diversificación y crecimiento de la demanda interna?.

Al mismo tiempo, otros investigadores han defendido que, a pesar de la amplia intervención reguladora del Estado, el presupuesto y los déficit públicos fueron reducidos en relación con la renta nacional durante la Restauración, por lo que no tuvieron influencia en su determinación ${ }^{10}$. La reducida capacidad de gasto del Estado estaba provocada por la insuficiencia de la Hacienda que imposibilitó la atención a las necesidades básicas de la economia, dedicando la mayor parte de los ingresos al pago del servicio de la deuda pública, a costa de la reducida importancia de los gastos en infraestructura y en los servicios económicos del presupuesto ${ }^{11}$. Las causas de las estrecheces presupuestarias fueron la insuficiencia y la rigidez del sistema fiscal, que trató desigualmente a sectores y grupos sociales y ejerció una menor presión fiscal que los sistemas tributarios de otros paises europeos ${ }^{12}$.

A pesar de la notable atención que estas ideas han recibido no han sido, todavia, objeto de contrastación detallada. La aceptación generalizada de la hipótesis de la vía nacionalista no ha provocado una investigación minuciosa de los efectos de las políticas sectoriales. Y si bien desde la publicación del libro de Comin ${ }^{13}$ disponemos de un análisis exhaustivo del presupuesto del Estado, su aportación no es, tampoco, un estudio detallado de la relación entre el presupuesto y la trayectoria seguida por los sectores industriales.

El objetivo de las páginas siguientes es aportar evidencia cuantitativa que pone en cuestión la segunda de las opiniones señaladas: la insignificancia del gasto público en la determinación de la evolución del nivel de renta española durante la Restauración. El artículo está organizado de la forma siguiente. En

8 Fraile (1985a).

- Maluquer (1987), p. 99.

10 Tedde (1981), p. 264; Martin Aceña y Comín (1987), pp. 249.256; Comin (1988), pp. 643. 644, 687 y 694.

11 Comin (1988), pp. 643.644 y 697.

12 Tedde (1981), pp. 264-265; Comin (1988), pp. 644 y 689.

13 Comin (1988). 
la próxima sección se describe el comportamiento de la economía durante el período estudiado. En la tercera se presenta un modelo para medir el impacto del gasto del Estado sobre el gasto nacional y la producción industrial. En la última sección se aporta evidencia cualitativa de los efectos que las políticas de gasto tuvieron sobre la industria, para llegar a la conclusión de que no puede defenderse, como se ha venido haciendo hasta ahora, que el presupuesto del Estado no tuviera influencia en la evolución de la economía española durante la Restauración.

Como se observa en el cuadro 1 , la reducción de las tasas de crecimiento que tuvo lugar durante la Restauración no supuso un estancamiento. El GNB aumentó entre $1870-1874$ y $1920-1923$ un 80 por 100 , lo que demuestra la relativa vitalidad de la economia, salpicada por periodos de recesión, como la segunda mitad de la década de los ochenta o estancamiento como los quinquenios 1880-1885 y 1905-1909. Crecimiento no continuo, por tanto, pero si intenso a lo largo de los cincuenta años del periodo.

Al contrario, el crecimiento de la producción industrial puede considerarse ininterrumpido y sostenido, a excepción de un ligero estancamiento en la segunda mitad de la década de los ochenta, coincidiendo con la fuerte caida del GNB. El resultado de unas tasas de crecimiento superiores a las del gasto nacional es el aumento de la importancia del sector secundario, aunque la modernización provocada por este hecho sea insuficiente ${ }^{14}$. La evolución de la producción de las industrias básicas es extraordinariamente parecida a la del conjunto del sector industrial. Solamente a partir de 1910-1914 el ritmo de crecimiento se ralentiza para transformarse en negativo a partir de entonces marcando, por tanto, una clara diferencia con el resto del sector.

El consumo privado era el principal componente del GNB, por lo cual la evolución de ambas variables presenta una pronunciada similitud. Debemos considerar un signo de modernización de la estructura de la economia española la pérdida continuada de importancia del consumo privado sobre el GNB, aunque los resultados obtenidos, reducción desde el 90 por 100 en $1870-1874$ hasta el 80 por 100 en 1920-1923, no sean muy espectaculares. Por otro lado,

\footnotetext{
14 Para una constatación del avance de la producción industrial en la composición del producto, véase la nota 26.
} 
la evolución del consumo presenta las mismas variaciones que el GNB: crisis en los años ochenta y estancamiento en el segundo quinquenio del siglo $\mathrm{xX}$.

\section{CUADRO 1}

Evolución del gasto nacional bruto, sus componentes y la producción industrial

\begin{tabular}{|c|c|c|c|c|c|c|c|}
\hline & Años & $C P R$ & $C P U$ & BISE & SUSA & INVPR & INVPUB \\
\hline $1870 / 74$ & & 100,00 & 100,00 & 100,00 & 100,00 & 100,00 & 100,00 \\
\hline $1875 / 79$ & & 113,60 & 133,38 & 139,47 & 130,12 & 152,53 & 118,99 \\
\hline $1880 / 84$ & & 112,30 & 127,68 & 134,27 & 124,16 & 216,22 & 194,94 \\
\hline $1885 / 89$ & & 97,66 & 148,25 & 143,77 & 150,64 & 178,04 & 220,25 \\
\hline $1890 / 94$ & & 111,78 & 137,18 & 119,58 & 146,60 & 216,05 & 194,94 \\
\hline $1895 / 99$ & & 115,35 & 140,45 & 137,92 & 141,80 & 228,89 & 191,14 \\
\hline $1900 / 04$ & & 138,20 & 127,44 & 97,82 & 143,29 & 351,18 & 153,16 \\
\hline $1905 / 09$ & & 137,43 & 139,38 & 114,55 & 152,66 & 338,85 & 191,14 \\
\hline $1910 / 14$ & & 141,94 & 185,28 & 174,32 & 191,15 & 433,95 & 306,33 \\
\hline $1915 / 19$ & & 148,24 & 178,56 & 233,10 & 149,37 & 331,08 & 202,53 \\
\hline $1920 / 23$ & & 160,93 & 270,59 & 359,81 & 222,84 & 514,36 & 455,70 \\
\hline & Añas & GPUB & Export & Import & GNB & IPIES & IPIB \\
\hline $1870 / 74$ & & 100,00 & 100,00 & 100,00 & 100,00 & 100,00 & 100,00 \\
\hline $1875 / 79$ & & 132,51 & 104,25 & 107,82 & 115,96 & 115,98 & 111,03 \\
\hline $1880 / 84$ & & 131,76 & 164,18 & 153,03 & 116,70 & 134,18 & 133,29 \\
\hline $1885 / 89$ & & 152,61 & 199,89 & 178,42 & 103,63 & 138,94 & 148,81 \\
\hline $1890 / 94$ & $\ldots$ & 140,68 & 209,30 & 176,03 & 120,13 & 161,06 & 161,99 \\
\hline $1895 / 99$ & & 143,52 & 298,91 & 149,75 & 128,36 & 174,04 & 171,73 \\
\hline $1900 / 04$ & & 129,00 & 233,84 & 150,78 & 148,62 & 200,54 & 190,29 \\
\hline $1905 / 09$ & & 142,51 & 271,79 & 161,32 & 148,98 & 216,44 & 214,15 \\
\hline $1910 / 14$ & & 192,62 & 315,35 & 183,53 & 160,72 & 239,02 & 229,75 \\
\hline $1915 / 19$ & & 180,01 & 328,81 & 136,94 & 168,86 & 257,22 & 217,47 \\
\hline $1920 / 23$ & $\ldots .$. & 281,80 & 268,40 & 183,03 & 180,99 & 268,91 & 198,34 \\
\hline
\end{tabular}

CPR. Consumo Privado; CPU: Consumo Público; BISE: Compra de Bienes y Servicios; SUSA: Sueldos y Salarios; INVPR. Inversión Privada; INVPUB: Inversión Püblica; GPUB: Gasto Público; Export: Exportaciones; Import: Importaciones; GNB: Gasto Nacional Bruto; IPIES: Indice de la Producción Industrial de España; IPIB: Indice de Producción de las Industrias Básicas.

Fuente: Elaborado a partir de Carreras (1981, 1984, 1985); Comin (1985); Tena (1989). 
La reducción de la importancia del consumo es consecuencia de su menor tasa de crecimiento que la inversión, principalmente, gasto público y exportaciones. La inversión privada se quintuplica durante el periodo considerado, lo que permite alcanzar un porcentaje del 8 por 100 del GNB, cuando en 1870 . 74 era apenas un 3 por 100. Ese crecimiento es mayor en el siglo xx (5,42 por 100 de tasa media anual) que en el XIX (4,29 por 100) y es especialmente relevante en los años posteriores a la primera guerra mundial.

\section{CUADRO 2}

Gastos del Estado en compras al sector privado como porcentaje del producto industrial. Medias quinquenales 1870-1923

\begin{tabular}{|c|c|c|}
\hline 374 & 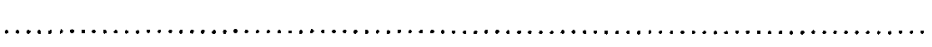 & 14,00 \\
\hline 1875.1879 & $\ldots$ & 16,63 \\
\hline $1880-1884$ & . & 17,14 \\
\hline 1885.1889 & & 21,50 \\
\hline $1890-1894$ & & 15,15 \\
\hline $1895-1899$ & .... & 16,09 \\
\hline $1900-1904$ & 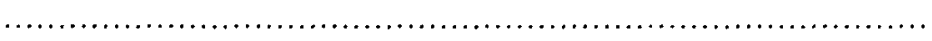 & 9,51 \\
\hline 1905.1909 & & 11,08 \\
\hline $1910-1914$ & ... & 16,38 \\
\hline 1915-1919 & 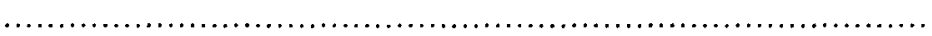 & 18,29 \\
\hline 1920.1923 & $\ldots$ & 22,81 \\
\hline
\end{tabular}

FUENTE: Cálculos propios, según el método explicado en el texto, a partir de Carreras, A (1985); Comin, F. (1985), y Alcaide, J. (1976).

El otro componente del GNB que va a mostrar un comportamiento muy dinámico es la inversión pública, dentro de una evolución del gasto público que multiplica su valor por 2,8 , lo que le permite aumentar su importancia dentro del gasto nacional. El comportamiento de la inversión es muy irregular, con un periodo de alza muy marcado entre 1870-1874 y 1885-1889 con una tasa de crecimiento medio anual del 6 por 100 , un estancamiento entre 1890-1894 y 1905-1909 (que incluye la reducción del gasto debido a la estabilización de Fernández Villaverde) y un nuevo crecimiento desde 1910-1914 hasta 1920-1923.

El consumo público, el otro componente del gasto público, presenta un crecimiento más lento pero menos irregular. La instauración del nuevo régimen supone un incremento del consumo que se frena en $1885-1889$ para 
sufrir un estancamiento primero (1890-1894 y 1895-1900) y una recesión después (1900-1904). El crecimiento se produce, como ocurria en la inversión, en la segunda y tercera década del siglo xx. Dentro del consumo coexisten dos componentes con evoluciones diferenciadas. Las compras de bienes y servicios son más afectadas por la coyuntura (descenso en 1890-1894, reflejo retardado de la crisis de los años ochenta) y por la estabilización de Fernández Villaverde, mientras el gasto en sueldos y salarios presenta una evolución más similar al de la inversión pública: crecimiento entre 1870-1874 y 1885-1889, estancamiento hasta 1905-1909 y nuevo crecimiento posterior.

La consecuencia de la diferente evolución de los componentes del gasto público es el aumento de la importancia de la formación bruta de capital fijo dentro de aquél, aunque en 1920-1923 no supondrá más que el 10 por 100. En cualquier caso, este aumento es el cambio más destacado en la composición del gasto del Estado, el cual mantiene una evolución irregular durante el período, con tasas de crecimiento superiores a las del GNB durante todo el siglo XIX, aunque estancadas o en ligera recesión en la última década. La instauración del nuevo régimen supuso un incentivo para el gasto, pero tal impulso se vio frenado a finales de siglo. Ese impulso no se recuperó hasta la segunda década del $\mathrm{xx}$, con elevados ritmos de crecimiento que culminan en el extraordinario aumento de los años veinte provocando que el gasto del Estado supere una participación del 10 por 100 en la generación del GNB.

En resumen, el crecimiento del gasto nacional durante la Restauración está enmarcado en un ligero, pero significativo, cambio estructural. Aumenta la importancia del sector secundario y se reduce la importancia del consumo privado, mientras se incrementa el porcentaje dedicado a inversión. Dentro del gasto del Estado también podemos, en este nivel de agregación, detectar algunos indicios de modernización de las estructuras. Crece la importancia del gasto en bienes y servicios y de la formación bruta de capital fijo reduciendo la del gasto en funcionarios. En la sección siguiente veremos cómo estos movimientos están relacionados y que el Estado puede considerarse inductor de los mismos.

\section{III}

En ocasiones anteriores se ha intentado la obtención de estimaciones de la relevancia de la intervención del gasto del Estado en la evolución de la renta nacional. El más reciente es el de Martín Aceña y Garcia Santos de estimar un 
multiplicador del gasto para España en el periodo 1900-1935 15. Estos investigadores estiman un modelo de forma estructural para la economía española con dos ecuaciones y una condición de equilibrio. Los multiplicadores obtenidos para el gasto público son crecientes para todo el periodo, desde un 0,28 en 1902-1904 hasta un 0,82 durante la Segunda República ${ }^{16}$. Los resultados que obtienen presentan, sin embargo, algunos aspectos discutibles. Como con anterioridad otros estudios ${ }^{17}$, el método para la estimación de la influencia del Estado (y, en su caso, también de la inversión privada) es la construcción de un modelo de comportamiento de la economía para el periodo de estudio. Un modelo estructural, por tanto, en el cual las ecuaciones representan el comportamiento de los agentes económicos, reflejado en los valores de los parámetros. La influencia del sector público se obtiene suponiendo que, en el modelo estimado, la variable de política económica, el gasto público, es cero o tiene el comportamiento conjeturado (por ejemplo, el reflejado por la tendencia seguida en años anteriores). La validez de esta manipulación se basa en la confianza de que la estructura del modelo no se verá alterada por tal decisión. Es este un supuesto dificil de mantener. Su significado es que los valores de los parámetros de sus ecuaciones no varian cualquiera que sea la decisión de gasto público. Es decir, los consumidores mantienen su propensión marginal al consumo constante exista o no gasto del Estado ${ }^{18}$. Y de la misma forma para los inversores se supone que lo relevante es, únicamente, el aspecto cuantitativo del gasto público y no la influencia que una diferente estructura del de gasto pueda tener en la generación de confianza entre el empresariado ${ }^{19}$.

Es dificil mantener que situaciones como las reseñadas no modifiquen la estructura de la economia, cuando conocemos que los individuos modifican su comportamiento y su forma de tomar decisiones ante diferentes regimenes de

13 Martin Aceña, Pablo, y Garcia Santos, Nieves (1990).

16 Los multiplicadores son inferiores a la unidad por el método de cálculo. Su interpretación, por tanto, no es la usual, el aumento en la renta consecuencia de un aumento unitario en el gasto público, sino el incremento en la tasa de crecimiento del Producto Nacional Bruto como consecuencia de un incremento de un 1 por 100 en la tasa de crecimiento en el gasto del Estado.

17 Hansen (1969), Pryor (1979), Craft (1981).

18 La importancia de tal suposición quedara más clara si consideramos que de ella se deriva, por ejemplo, que el comportamiento del consumidor, representado por la propensión marginal al consumo, no variaria si el gobierno decidiera establecer un sistema de seguridad social, con los efectos de reducción del ahorro privado que supone tal medida, respecto al caso en el cual no existiera gasto público y, por tanto, la previsión social debiera ser realizada por los propios consumidores. En aquellos momentos las decisiones relevantes de los consumidores estarian determinadas, en relación con el gasto público, por los gastos sociales del Estado, que, aunque reducidos, deben ser tenidos en cuenta.

19 Como reconocia Keynes, éste es un elemento de gran importancia en la toma de las decisiones de inversión. Keynes (1936), cap. 12. 
política económica, como ha puesto de relieve la critica de las expectativas racionales 20 . Si esto ocurre, la validez del ejercicio realizado se reduce y obliga a buscar métodos alternativos de estimación de los efectos del gasto público.

Otro aspecto que seria interesante que captara un modelo es la influencia de la estructura del presupuesto, compuesto por partidas de carácter heterogéneo: compras de bienes, sueldos y salarios, formación bruta de capital. Los modelos agregados, a través del cálculo del multiplicador, no consiguen captar esta diversidad de efectos.

Por todo lo señalado, para estimar cuantitativamente la influencia del gasto público sobre la economía se ha preferido la utilización de un modelo de vector autorregresivo no restringido (VAR), que ha sido propuesto para evitar los problemas a los que nos hemos referido ${ }^{21}$ y que, a pesar de su relativa juventud, ya ha sido empleado en estudios de historia económica 22 . Un vector autorregresivo es un sistema lineal de ecuaciones estocásticas en diferencias que, para todo $t$, puede escribirse ${ }^{23}$ :

$$
Y(t)=C+\sum_{s=1}^{m} A_{s} Y(t-s)+u(t)
$$

donde $Y$ es un vector $n \times 1$; C es un vector $n \times 1$ de términos constantes; cada $A s$ es una matriz $n \times n$ de coeficientes para $s=1$ hasta $m$, y $u$ es un vector $n \times 1$ de residuos, identificado por la propiedad de que $u(t)$ no está correlacionado con $Y(s)$ cuando $s<t$. Como se observa, un modelo VAR consta de un número de ecuaciones igual al número de variables consideradas. Todas ellas son consideradas endógenas, es decir, cada una es determinada por las demás; en consecuencia, el sistema de ecuaciones no representa el comportamiento de la economia (por tanto, no es un modelo de forma estructural). Su objetivo fundamental es especificar un modelo que refleje, lo más fielmente posible, las regularidades empíricas e interacciones entre las variables objeto de análisis ${ }^{24}$. Ello no significa la ausencia de una teoría económica que sustente la modeliza-

20 Lucas (1976), Sargent y Wallace (1976).

${ }^{21}$ Sims (1982). Un relato con mayor grado de detalle sobre los problemas que intentan solventar los modelos de vectores autorregresivos, en Darnell y Evans (1990), pp. 113-118.

22 Por ejemplo, en Capie, Mills y Wood (1991), para hallar las causas de la crisis monetaria de finales del siglo xix en Gran Bretaña.

${ }^{23}$ Se puede obtener información sobre los vectores autorregresivos en Sargent (1979), cap. 3, y Doan (1988), cap. 8. Su utilización para valorar la política económica, en Sims (1980 y 1982). Recientemente han sido objeto de reconsideración también por Sims (1992). Para un uso de los modelos VAR similar al que en este articulo se pretende, Garcia Mila (1987).

24 Ballabriga (1992). 
ción. Resulta evidente por la elección de variables y las explicaciones que siguen que se está suponiendo, implicitamente, una economía con una estructura tipicamente keynesiana.

El estudio de las interacciones dinámicas estimadas es una de las motivaciones fundamentales en el uso de los modelos VAR. La utilización típica es la determinación de la influencia de una variación no anticipada de una variable sobre las demás a través del cálculo de las funciones impulso-respuesta y de la descomposición de la varianza del error de predicción 25 . Por ello, estos modelos son de gran utilidad para analizar cambios en la política económica.

Las variaciones que vamos a tener en consideración son las provocadas por una separación del gasto público de un régimen preestablecido, es decir, una modificación en lo que había sido la política hasta ese momento, en el sentido de que la evolución anterior de esa variable no nos hubiera permitido predecirla. Por ejemplo, el cambio no anticipado y no permanente en los gastos militares del Estado debido a la realización de un programa de construcciones navales con un período de ejecución fijo. En el lenguaje de los modelos VAR a esa variación no predicha se le llama «innovación». La hipótesis que se pretende contrastar es la influencia que una innovación en el gasto público, o cualquiera de sus componentes, tiene sobre el resto de variables del sistema (consumo, inversión, GNB, producción industrial).

Se han estimado tres grupos de sistemas de ecuaciones. En el primero se ha introducido la identidad macroeconómica del GNB, con el objetivo de medir la influencia del gasto público sobre el gasto nacional, estimándose dos sistemas diferentes de ecuaciones, en función del nivel de agregación del gasto estatal. Los sistemas cuentan con las siguientes variables ${ }^{26}$ :

$$
\begin{aligned}
& \text { XM, GPUB, INVPR, CPR, GNB } \\
& \text { XM, INVPUB, INVPR, CPU, CPR, GNB. }
\end{aligned}
$$

En los otros dos grupos de sistemas se ha sustituido el GNB por el IPIES y el IPIB, respectivamente.

2s Para evitar la correlación contemporanea durante el proceso de estimación, lo que haría indistinguible la influencia de cada variable sobre las demás, se requiere proceder a la ortogonalización del sistema. Como sugiere Leamer (1985), tal ortogonalización no puede ser arbitraria y debe estar basada en consideraciones de teoria económica. En nuestro caso, la ordenación se ha realizado de mayor a menor exogeneidad en el modelo, de forma que la más exógena se ha con. siderado las exportaciones netas y la menor el consumo privado. Entre ambas se encuentran las variables püblicas y la inversión privada. Para realizar la ordenación se han realizado tests de causalidad de Granger a todas la variables.

26 Para una descripción de los datos, véase el apéndice $\mathrm{A}$. 
Todos los sistemas de ecuaciones han sido estimados con dos y cuatro retardos y la primera especificación fue contrastada como una restricción de la segunda. En todos los casos el menor número de retardos fue aceptado. El período para el cual ha sido realizada la estimación es 1874-1923. Las variables fueron transformadas en números índices (base 100 en 1913) y tomadas en niveles ${ }^{27}$.

\section{GRAFICO 1}

\section{Respuestas a innovaciones en el gasto público}

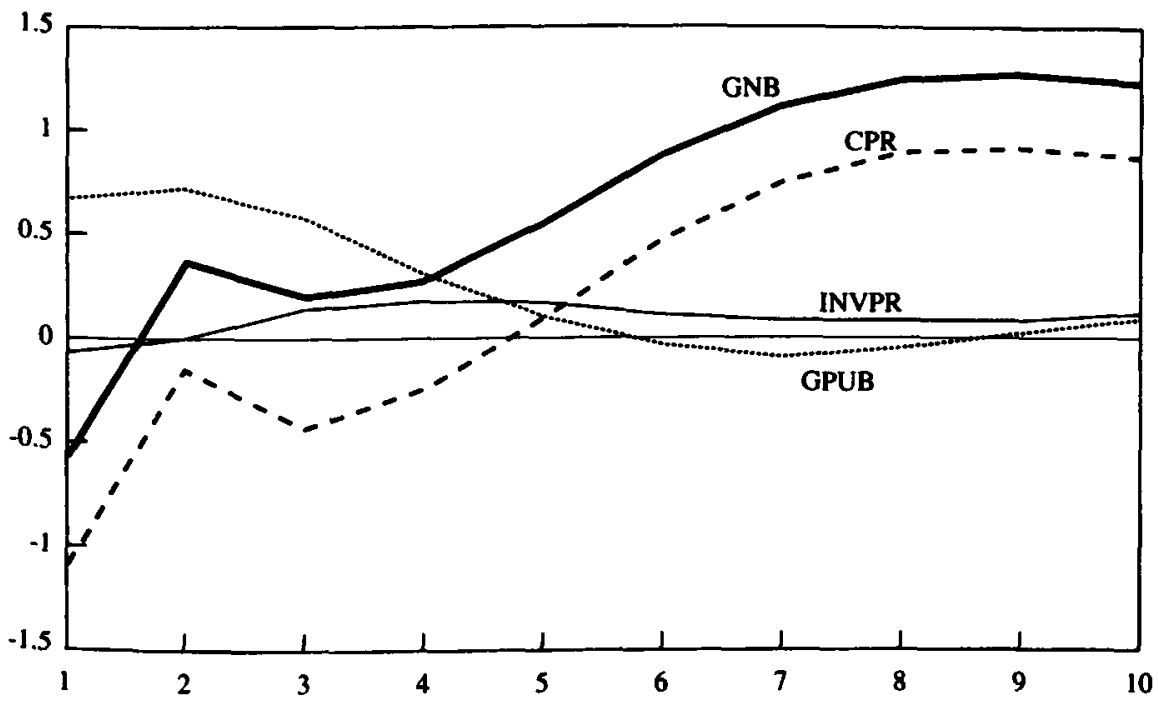

Fuente: Véase texto.

El gráfico 1 presenta la función impulso-respuesta del GNB a una innovación en el gasto público en el primer sistema de ecuaciones. Como se ha explicado, se puede considerar la innovación en el gasto público como el cambio no previsto por la evolución anterior de la variable. En este caso lo interpretaremos como una variación en la política fiscal. Frente a tal innovación, equivalente a una desviación standar unitaria, el GNB presenta una respuesta persistente y positiva: los efectos generados sobre el gasto nacional bruto, directa o

27 Para una mayor información sobre el tipo de modelización empleada en este artículo y para una presentación detallada de lus resultados, dirigirse al autor. 
indirectamente a través de efectos inducidos sobre el resto de componentes del gasto nacional, provocan un proceso expansivo de la economia, representado por la separación de la función respecto del eje de coordenadas.

\section{CUADRO 3}

Porcentaje de descomposición de la varianza, tres, seis y diez años adelante, en un sistema donde el GNB se define como $G N B=X M+G P U B+I N V P R+C P R$

\begin{tabular}{lrrrrrr}
\hline & \multicolumn{7}{c}{ Varianza del emor de } \\
\cline { 2 - 7 } Innovación de la variable & \multicolumn{7}{c}{ XM } & GPUB & INVPR & CPR & GNB \\
\cline { 2 - 7 } XM & & & & & & \\
& 3 & 89,8 & 30,4 & 5,3 & 9,3 & 4,9 \\
& 6 & 86,0 & 30,2 & 5,3 & 12,5 & 11,2 \\
GPUB & 10 & 79,0 & 39,1 & 11,8 & 12,8 & 13,8 \\
& 3 & 0,9 & 574 & 1,4 & 2,8 & 0,8 \\
& 6 & 3,2 & 48,8 & 4,0 & 2,7 & 2,0 \\
INVPR & 10 & 7,0 & 41,9 & 4,9 & 6,1 & 6,8 \\
& 3 & 7,2 & 11,4 & 86,6 & 10,8 & 22,6 \\
& 6 & 7,2 & 19,6 & 83,1 & 22,5 & 37,0 \\
CPR & 10 & 10,5 & 17,7 & 76,8 & 30,1 & 42,7 \\
& 3 & 1,9 & 0,8 & 6,7 & 77,1 & 71,5 \\
& 6 & 3,6 & 1,2 & 7,6 & 62,2 & 49,8 \\
& 10 & 3,4 & 1,2 & 6,4 & 51,0 & 36,6 \\
\hline
\end{tabular}

Como puede intuirse, el proceso que estamos describiendo presenta grandes semejanzas con el concepto tradicional del multiplicador: ante un movimiento autónomo, generado por cambios en la política económica, la función impulso-respuesta dibuja el cambio inducido en la variable representada, en este caso el GNB. Sin embargo, al tratar de captar el comportamiento dinámico de la economia el ratio que más se aproxima al multiplicador es la relación entre la respuesta del GNB a una innovación en el gasto público y la respuesta del gasto público a su propia innovación. Con esta medida se pretende captar, en cada momento del tiempo, la influencia sobre el GNB de la variación en el gasto estatal debida a la innovación inicial. Como puede comprobarse por la representación gráfica, a partir del quinto periodo el ratio es claramente superior a uno, mostrando el efecto expansivo del presupuesto.

El método de estimación que estamos utilizando nos permite distinguir 
aquellos componentes del GNB que actúan como correa de transmisión de los impulsos del gasto estatal. Ante la innovación del gasto público es el consumo privado el componente que recibe un mayor impacto, en parte debido al propio efecto del crecimiento del GPUB y en parte al efecto de realimentación derivado del propio crecimiento del GNB. Por otro lado, el efecto del gasto estatal sobre la inversión privada, aunque positiva, es reducido.

\section{GRAFICO 2}

\section{Respuestas a innovaciones en el consumo público}

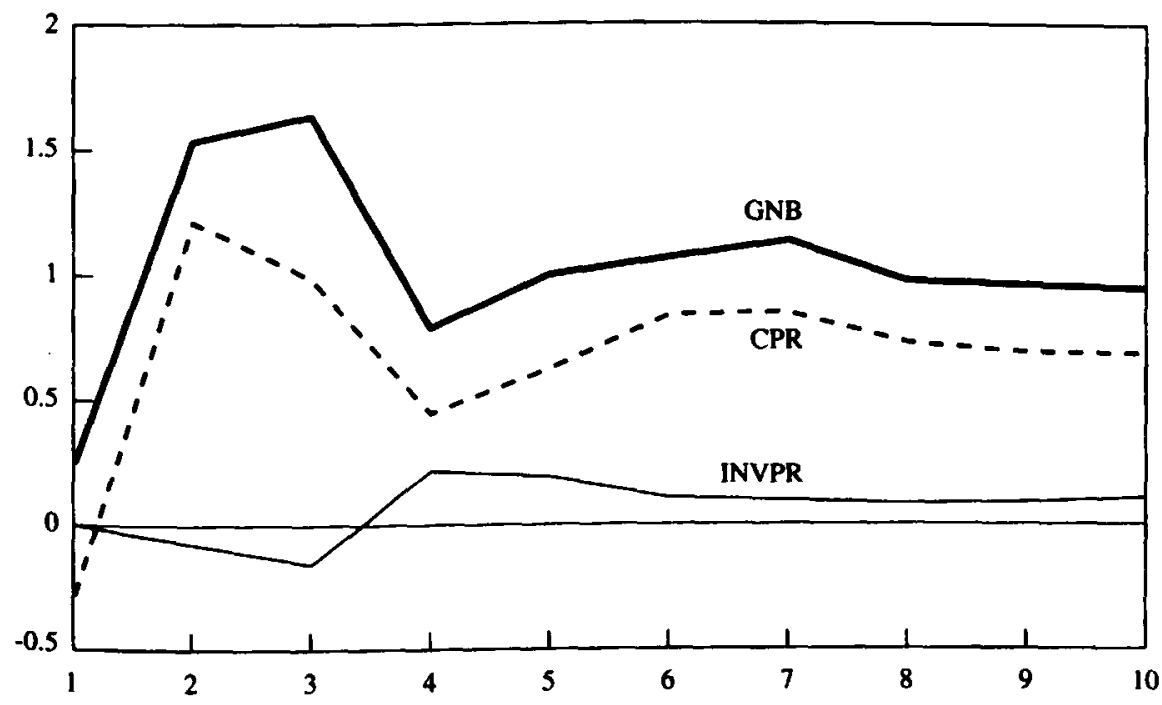

Fuente: Véase texto.

Para tener una idea completa, en esta primera aproximación, de la importancia de la variación inducida por las magnitudes presupuestarias es necesario preguntarse qué porcentaje de la varianza del gasto nacional es explicado por la variación del GPUB. Es decir, aunque conocemos que un cambio en esta variable provoca un movimiento expansivo en el GNB, no sabemos la importancia que el crecimiento provocado por el gasto tiene en la variación total del GNB. Podemos encontrar una primera respuesta en el cuadro 3. Es un cuadro de doble entrada que representa verticalmente y para cada período el porcentaje de la varianza del error de predicción de cada variable, de forma que la suma de la varianza explicada por la innovación de todas las variables es el 
cien por cien. Horizontalmente se expresa la importancia de cada variable en la explicación de la variación de las demás.

Si nos fijamos en la última columna, que recoge la varianza del error del GNB, comprobamos que, a corto plazo, la mayor parte de su variación es explicada por la innovación del consumo privado: casi en sus tres cuartas partes en el tercer periodo. Lo que ya era evidente si se atiende a la similitud de la función impulso-respuesta de las dos variables. A largo plazo, la importancia de la inversión privada crece hasta convertirse en dominante. Por su parte, el gasto público incrementa su importancia conforme consideramos un mayor número de períodos, de la misma forma que veiamos ocurría en el gráfico 1, hasta llegar a explicar en torno al 7 por 100. Esta podría ser una estimación aproximada de la importancia del gasto público en la determinación del gasto nacional, aunque, como veremos más adelante, el porcentaje puede modificarse al alza.

Una posibilidad que nos ofrece la utilización de los modelos VAR es la identificación de los componentes del gasto público que son más relevantes en la evolución del GNB. Para ello, se ha estimado un nuevo sistema de ecuacio-

\section{GRAFICO 3}

\section{Respuestas a innovaciones en la inversión pública}

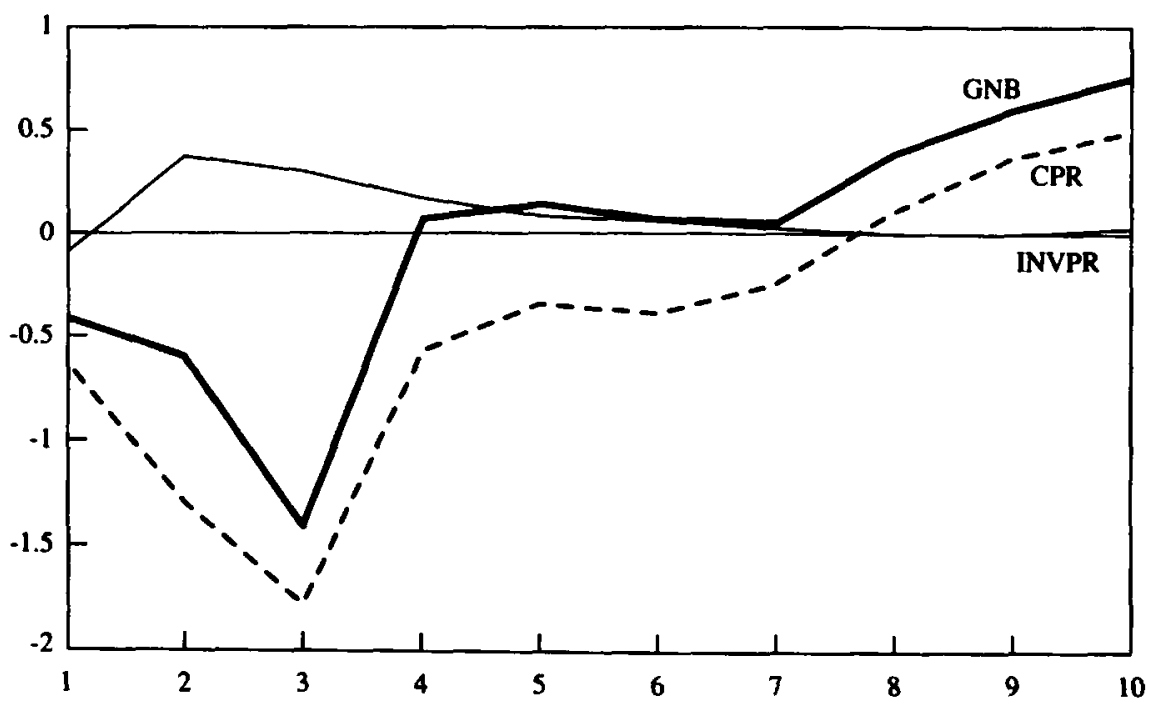

FuentE: Véase texto. 
nes en el cual el gasto del Estado se ha dividido en sus dos componentes principales: la inversión pública y el consumo público. Los resultados pueden verse en el gráfico 2. El efecto más importante corresponde a los gastos corrientes del Estado. El producto de una innovación en el consumo es un movimiento positivo y sostenido, con su punto más elevado en los tres primeros años. De la misma forma que veiamos en el gráfico 1, el proceso de transmisión de la innovación en el consumo público hacia el GNB se realiza a través del consumo privado: el incremento del gasto del Estado provoca un aumento del consumo del sector privado en un porcentaje menor que el aumento del GNB, pero con un perfil muy semejante. Ninguna otra variable de las presentes en el sistema es sensible a la variación del consumo público.

\section{CUADRO 4}

Porcentaje de descomposición de la varianza, tres, seis y diez años adelante, en un sistema donde el $G N B$ se define como $G N B=X M+I N V P U B+I N V P R+C P U+C P R$

\begin{tabular}{lrrrrrrr}
\hline \multirow{2}{*}{$\begin{array}{l}\text { Innovación } \\
\text { de la variable }\end{array}$} & \multicolumn{7}{c}{ Varianza del error de } \\
\cline { 2 - 8 } & & $X M$ & $I N V P U B$ & $I N V P R$ & $C P U$ & CPR & GNB \\
\hline \multirow{2}{*}{ XM } & 3 & 87,8 & 27,5 & 3,5 & 29,1 & 13,0 & 8,2 \\
& 6 & 85,3 & 22,9 & 5,4 & 26,6 & 24,4 & 24,1 \\
& 10 & 77,6 & 29,0 & 20,4 & 36,7 & 32,4 & 35,6 \\
INVPUB & 3 & 4,2 & 57,4 & 11,7 & 21,3 & 9,4 & 4,1 \\
& 6 & 5,0 & 52,8 & 11,1 & 27,9 & 7,6 & 2,6 \\
& 10 & 10,0 & 46,9 & 8,8 & 23,6 & 6,8 & 2,8 \\
INVPR & 3 & 4,8 & 8,2 & 77,2 & 5,9 & 19,8 & 35,8 \\
& 6 & 4,3 & 17,0 & 72,5 & 12,2 & 23,2 & 32,9 \\
& 10 & 5,9 & 17,2 & 60,8 & 11,4 & 21,1 & 28,2 \\
CPU & 3 & 0,7 & 6,5 & 1,3 & 43,4 & 4,7 & 8,6 \\
& 6 & 1,7 & 5,1 & 4,6 & 31,7 & 5,2 & 8,6 \\
& 10 & 3,1 & 4,6 & 4,8 & 26,9 & 6,8 & 9,7 \\
CPR & 3 & 2,3 & 0,4 & 6,2 & 0,3 & 53,0 & 48,4 \\
& 6 & 3,6 & 2,2 & 6,4 & 1,5 & 39,5 & 31,6 \\
& 10 & 3,4 & 2,1 & 5,1 & 1,3 & 32,7 & 23,5 \\
\hline
\end{tabular}


A diferencia de lo que acabamos de comentar, la formación bruta de capital del Estado muestra un efecto negativo a corto plazo sobre el GNB y un efecto persistente e importante a largo plazo. La inversión estatal tiene un ligero efecto expansivo sobre la inversión privada pero, sin embargo, provoca un efecto negativo sobre el consumo privado, como se contempla en el gráfico 3 . A corto plazo, pues, un incremento en la inversión pública reducía el consumo pero incrementaba la inversión, induciendo un mayor gasto en formación de capital por parte del sector privado. A largo plazo, el consumo se recuperaba.

\section{CUADRO 5}

Porcentaje de descomposición de la varianza, tres, seis y diez años adelante en un sistema donde las variables son XM, GPUB, INVPR, CPR e IPIES

\begin{tabular}{|c|c|c|c|c|c|c|}
\hline \multirow{2}{*}{ Innovación de la variable } & \multicolumn{6}{|c|}{ Varianze del error de } \\
\hline & & $X M$ & GPUB & INVPR & $C P R$ & IPIES \\
\hline \multirow{3}{*}{$\mathrm{XM}$} & 3 & 84,0 & 32,4 & 19,8 & 7,3 & 3,3 \\
\hline & 6 & 77,8 & 32,7 & 19,2 & 7,3 & 9,8 \\
\hline & 10 & 73,5 & 34,6 & 16,8 & 7,1 & 8,8 \\
\hline \multirow[t]{3}{*}{ GPUB } & 3 & 1,6 & 58,6 & 0,8 & 2,7 & 3,1 \\
\hline & 6 & 3,3 & 51,7 & 2,7 & 2,5 & 9,0 \\
\hline & 10 & 6,5 & 47,3 & 3,3 & 4,8 & 10,6 \\
\hline \multirow[t]{3}{*}{ INVPR } & 3 & 7,4 & 6,3 & 62,9 & 13,6 & 26,6 \\
\hline & 6 & 6,8 & 11,1 & 60,0 & 20,1 & 34,4 \\
\hline & 10 & 8,1 & 10,2 & 57,3 & 22,2 & 36,2 \\
\hline \multirow[t]{3}{*}{ CPR } & 3 & 2,3 & 0,7 & 5,3 & 74,9 & 17,0 \\
\hline & 6 & 4,9 & 1,1 & 5,8 & 63,7 & 8,3 \\
\hline & 10 & 4,6 & 1,1 & 5,4 & 55,3 & 5,7 \\
\hline \multirow[t]{3}{*}{ IPIES } & 3 & 4,4 & 1,8 & 10,9 & 1,3 & 49,7 \\
\hline & 6 & 6,9 & 3,2 & 12,0 & 6,2 & 38,3 \\
\hline & 10 & 7,2 & 6,5 & 16,9 & 10,3 & 38,4 \\
\hline
\end{tabular}

Como antes, es necesario preguntarse por la relevancia que tienen estos movimientos en la evolución del GNB. El cuadro 4 representa la descomposición de la varianza de esta variable. Puede observarse que el principal determinante de su variación a corto plazo es el consumo privado y a largo plazo la 
inversión privada. De las dos variables públicas el consumo explica un porcentaje de la variación en torno al 8-9 por 100, mientras la inversión lo hace en un 2 por 100. En conjunto, el gasto del Estado llega a explicar un 10 por 100 de la variación del gasto nacional. Estos datos confirman la conclusión presentada más arriba: el gasto público determinó la evolución del GNB español durante la Restauración en un porcentaje no desdeñable, siendo, a corto plazo, los gastos corrientes los más importantes en la explicación de esa variación, mientras los gastos de capital adquieren relevancia a largo plazo.

Sin embargo, la observación aislada de estas conclusiones puede conducir a la infravaloración de su importancia durante la Restauración. Un porcentaje cercano a las tres cuartas partes del producto nacional se obtenía en el sector agrario, sobre el cual el impacto de los gasto estatales era reducido, a excepción de la parte dedicada al pago de sueldos y salarios, por cuanto las pautas del gasto de los funcionarios eran similares a las del resto de la población y en ella predominaba el consumo de bienes agrarios debido a la reducida renta per cápita que impedía a la mayoría de los españoles el acceso al consumo de productos industriales. En este razonamiento se encuentra la justificación de la relevancia del consumo público en la explicación de la evolución del gasto nacional.

Pero, a diferencia de los agentes privados, la estructura del gasto del Estado está más inclinada hacia la adquisición de bienes del sector industrial. Desde el material de administración hasta la construcción de carreteras, la obra pública por excelencia, un gran número de actividades estatales repercutian, principalmente, sobre el sector industrial, no sobre el agrario. Por tanto, la comparación de la evolución del gasto del Estado con la variación de la producción industrial puede ayudarnos a precisar los efectos del presupuesto sobre la economia y sobre su sector más dinámico, el industrial. En el cuadro 2 se ha intentado realizar una cuantificación de esta hipótesis. Se ha supuesto que el porcentaje del Gasto Nacional Bruto generado por la industria es del 20 por 100 para todos los quinquenios de la tabla, excepto para 1920-1923, que se ha considerado del 25 por $100^{28}$. Para calcular el valor que suponen las compras del Estado en el sector industrial se ha restado de las compras de bienes y servicios el porcentaje que sobre ellas supone el gasto en agricultura según la clasificación funcional ${ }^{29}$. Los resultados obtenidos llaman

\footnotetext{
23 Los valores de la industria dentro del GNB provienen, por aproximación, de las estimaciones realizadas por Julio Alcaide sobre la distribución del Producto Interior Bruto. Los valores medios que se obtienen de los datos de Alcaide son: 1901-1905, 19,88; 1906-1910, 20,72; 1911 1915, 20,7; 1916-1920, 21,24; 1921-1923, 26,93. Alcaide (1976). reducidos.

Se considera, por tanto, que los gastos del Estado en el sector servicios son nulos o muy
cidos.
} 
la atención por la importancia que representa el gasto estatal directo sobre la producción industrial. Durante las décadas finales del siglo xIX alcanza su valor más reducido en 1870-1874, antes de la instauración del régimen restauracionista. Dentro del nuevo régimen los valores superan siempre el 15 por 100 , alcanzando el 21 por 100 en el quinquenio 1885-1889, en consonancia con el incremento de la participación del gasto estatal en el GNB. Los dos primeros quinquenios del siglo $\mathrm{xx}$ muestran los efectos de la estabilización de Fernández Villaverde, con los valores más bajos de todo el periodo, en torno al 10 por 100 , para crecer a partir de ese momento.

\section{CUADRO 6}

Poncentaje de descomposición de la varianza, tres, seis y diez años adelante en un sistema donde las variables son XM, GPUB, INVPR, CPR e IPIB

\begin{tabular}{|c|c|c|c|c|c|c|}
\hline \multirow{2}{*}{ Innovación de la variable } & \multicolumn{6}{|c|}{ Varianze del error de } \\
\hline & & $X M$ & GPUB & INVPR & $C P R$ & IPIB \\
\hline \multirow[t]{3}{*}{$\mathrm{XM}$} & 3 & 78,2 & 23,6 & 20,8 & 7,3 & 0,2 \\
\hline & 6 & 68,5 & 26,1 & 19,2 & 8,3 & 8,2 \\
\hline & 10 & 64,5 & 33,2 & 18,2 & 8,3 & 8.6 \\
\hline \multirow[t]{3}{*}{ GPUB } & 3 & 0,0 & 53,9 & 2,6 & 5,9 & 1,1 \\
\hline & 6 & 2,5 & 44,8 & 3,3 & 5,9 & 6,7 \\
\hline & 10 & 6,0 & 35,2 & 4,1 & 7,4 & 8,9 \\
\hline \multirow[t]{3}{*}{ INVPR } & 3 & 13,2 & 9,9 & 67,4 & 14,6 & 12,0 \\
\hline & 6 & 11,6 & 12,4 & 66,2 & 17,3 & 21,6 \\
\hline & 10 & 13,1 & 10,3 & 59,8 & 18,1 & 26,3 \\
\hline \multirow[t]{3}{*}{ CPR } & 3 & 1,7 & 1,2 & 8,6 & 67,9 & 1,7 \\
\hline & 6 & 3,8 & 2,2 & 9,7 & 63,7 & 1,2 \\
\hline & 10 & 3,7 & 2,0 & 8,8 & 57,0 & 1,7 \\
\hline \multirow[t]{3}{*}{ IPIB } & 3 & 6,8 & 11,1 & 0,3 & 4,0 & 84,6 \\
\hline & 6 & 13,4 & 14,3 & 1,4 & 4,6 & 62,1 \\
\hline & 10 & 12,5 & 18,9 & 8,8 & 8,8 & 54,2 \\
\hline
\end{tabular}

La importancia del porcentaje que suponen los gastos del Estado sobre la industria justifica que intentemos calcular el impacto directo e indirecto de esos gastos sobre la producción industrial. Por ello, se ha sustituido en los 


\section{GRAFICO 4}

Respuesta de la producción industrial a una innovación en el gasto puiblico

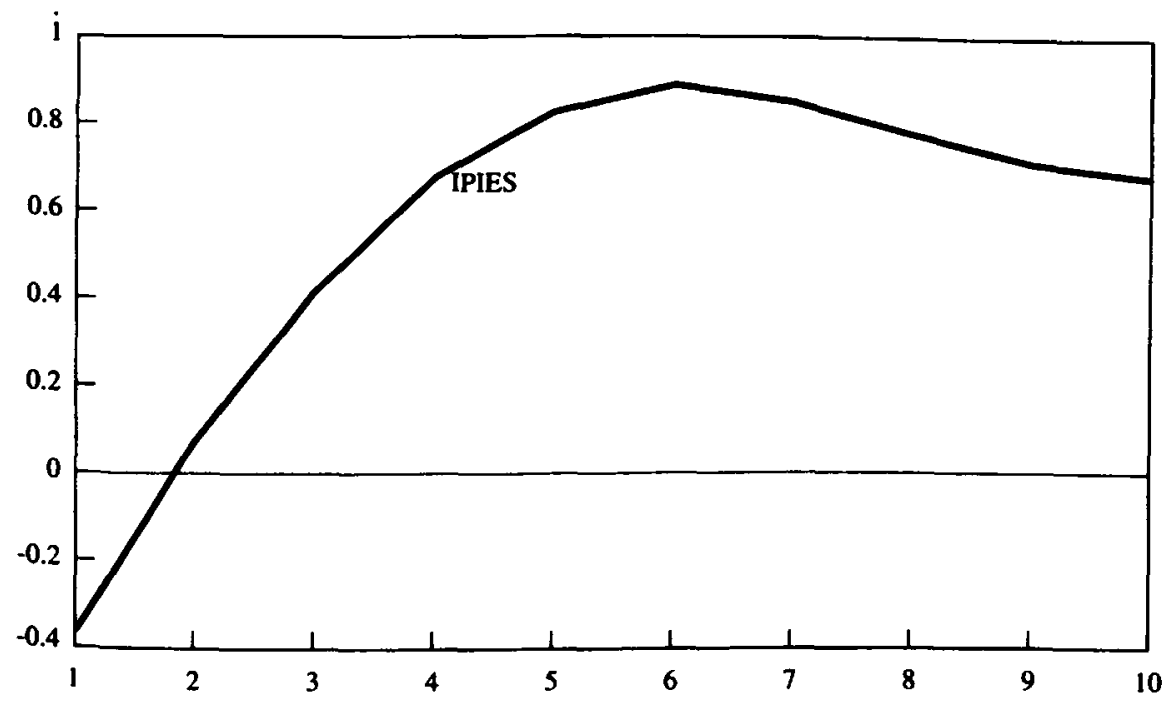

Fuente: Véase texto.

modelos de vectores autorregresivos presentados el Gasto Nacional Bruto por el Indice de Producción Industrial (IPIES), en primer lugar, y posteriormente por el Indice de Producción de las Industrias Básicas (IPIB).

El gráfico 4 presenta la respuesta de la producción industrial a una innovación en el gasto público. El resultado es un crecimiento de la actividad industrial, importante y sostenido a largo plazo, determinado, en esta ocasión, no por el consumo, como veiamos antes, sino por la innovación en la inversión pública (gräfico 5). Por tanto, la politica pública de formación de capital tuvo un importante efecto sobre la evolución de la producción industrial, que podemos cifrar en torno al 20 por 100 , a largo plazo, de la varianza explicada por los gastos de inversión (cuadro 7). Por el contrario, el consumo público, aunque tenga un efecto positivo sobre el producto, es decir, su aumento provoque un aumento de la producción industrial, explica apenas un 5 por 100 de su variación. En conjunto, lo llamativo es que las variables públicas pueden llegar a explicar una cuarta parte de la variación global de la producción industrial, lo cual es una buena muestra de la relevancia de la actuación del Estado en la determinación de la actividad del sector privado de la econo- 


\section{GRAFICO 5}

Respuestas del IPIES a innovaciones en el consumo y la inversión pública

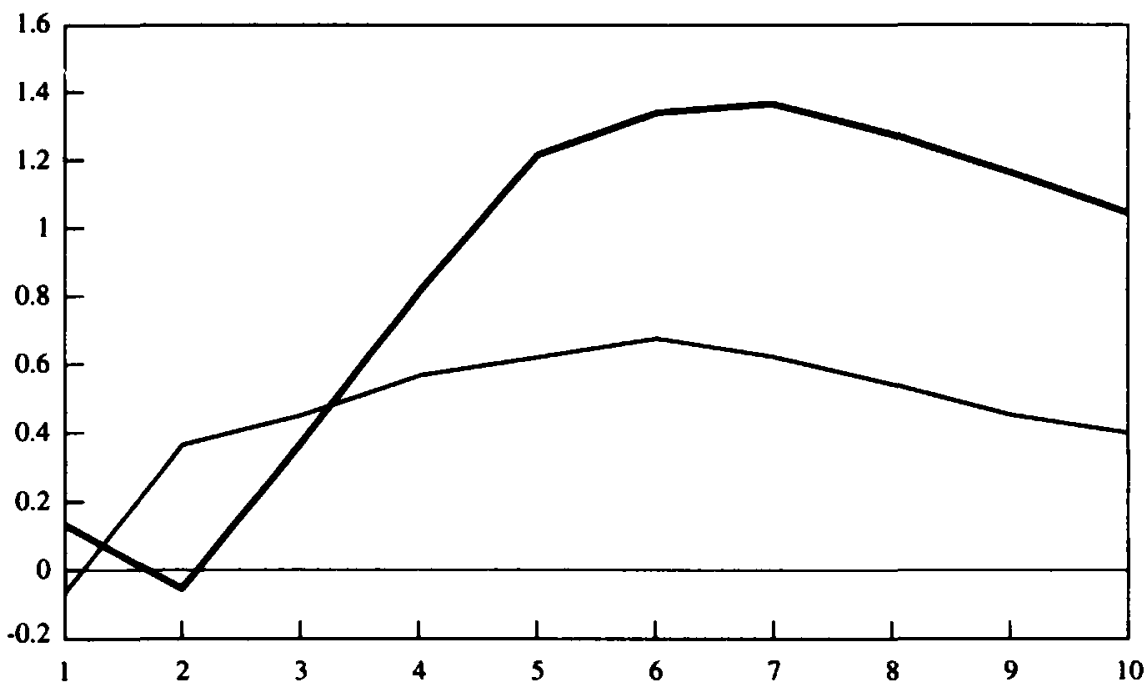

FUENTE: Véase texto.

mía española durante la Restauración. Todo ello a pesar de que los principales determinante de la evolución de la producción eran la inversión privada y el consumo privado, aunque este último sólo a corto plazo. Además, hay que señalar el destacado comportamiento inercial de la evolución de la producción industrial: en torno a un tercio de su evolución era debida a su variación en años anteriores.

Estas conclusiones se corroboran si consideramos ahora, en sustitución del indice de producción industrial, la influencia del Estado sobre la producción de las industrias básicas. Lo que se analiza, por tanto, es la influencia del presupuesto sobre las industrias recogidas en el IPIB, es decir, la mineria, las industrias metálicas básicas, la química, los cementos y la producción de energia eléctrica.

Hay que resaltar de nuevo el carácter fuertemente inercial que presenta la producción básica (cuadro 6). Cerca del 80 por 100 de la varianza de la evolución de la producción es explicada por la variación previa del mismo indice, a corto plazo, y hasta el 50 por 100 en un plazo de diez periodos. Del resto de variables, la inversión privada explica hasta una cuarta parte, mientras el gasto del Estado se aproxima, a largo plazo, al 10 por 100. 


\section{CUADRO 7}

Porcentaje de descomposición de la varianza, tres, seis y diez años adelante en un sistema donde las variables son XM, INVPUB, INVPR, CPU, CPR e IPIES

\begin{tabular}{|c|c|c|c|c|c|c|c|}
\hline \multirow{2}{*}{$\begin{array}{l}\text { Innovación } \\
\text { de la variable }\end{array}$} & \multicolumn{7}{|c|}{ Varianza del error de } \\
\hline & & $X M$ & INVPUB & INVPR & $C P U$ & CPR & IPIES \\
\hline \multirow[t]{3}{*}{$\mathrm{XM}$} & 3 & 79,9 & 31,8 & 16,0 & 26,0 & 11,1 & 3,6 \\
\hline & 6 & 74,6 & 33,4 & 16,7 & 24,2 & 14,3 & 8,6 \\
\hline & 10 & 64,3 & 32,4 & 14,8 & 27,5 & 14,3 & 9,4 \\
\hline \multirow[t]{3}{*}{ INVPUB } & 3 & 7,7 & 56,5 & 9,0 & 22,1 & 8,4 & 1,4 \\
\hline & 6 & 10,3 & 51,4 & 9,6 & 28,2 & 8,4 & 15,3 \\
\hline & 10 & 19,7 & 49,0 & 9,9 & 26,9 & 11,0 & 20,8 \\
\hline \multirow[t]{3}{*}{ INVPR } & 3 & 4,8 & 3,3 & 63,8 & 3,4 & 20,4 & 39,2 \\
\hline & 6 & 4,4 & 6,0 & 59,6 & 6,9 & 23,2 & 39,6 \\
\hline & 10 & 6,0 & 6,3 & 57.7 & 6,2 & 23,3 & 38,2 \\
\hline \multirow[t]{3}{*}{$\mathrm{CPU}$} & 3 & 0,5 & 6,2 & 0,9 & 44,4 & 5,0 & 3,2 \\
\hline & 6 & 1,0 & 5,4 & 2,0 & 35,6 & 4,8 & 5,5 \\
\hline & 10 & 2,1 & 5,5 & 2,2 & 31,1 & 5,5 & 5,3 \\
\hline \multirow[t]{3}{*}{ CPR } & 3 & 2,3 & 0,2 & 6,2 & 0,4 & 53,4 & 17,1 \\
\hline & 6 & 3,1 & 1,8 & 7,0 & 1,1 & 42,2 & 9,5 \\
\hline & 10 & 2,7 & 2,1 & 7,0 & 1,0 & 37,3 & 7,9 \\
\hline \multirow[t]{3}{*}{ IPIES } & 3 & 4,6 & 2,5 & 3,8 & 3,4 & 1,4 & 35,2 \\
\hline & 6 & 6,3 & 1,7 & 4,8 & 3,7 & 6,7 & 21,1 \\
\hline & 10 & 4,9 & 4,4 & 8,2 & 6,9 & 8,2 & 18,2 \\
\hline
\end{tabular}

Si se complementan estos datos con los del gráfico 6 puede comprobarse que el resultado de una innovación en el gasto público es el crecimiento de la producción básica. Es decir, el incremento de las cantidades gastadas por el Estado contribuía a la ampliación de la actividad productiva en el sector de industrias básicas, esencial para cualquier economia en crecimiento.

$\mathrm{Y}$, como hemos visto en el caso de la producción industrial, el componente del gasto público que tiene un efecto más importante es la inversión públiCa, mientras el consumo apenas logra tener un minimo efecto. El gráfico 7 muestra que los efectos generados por una innovación en la formación bruta de capital, en su momento de mayor impacto, son dos veces más significativas 
que las provocadas por el gasto corriente del Estado. Resultado plenamente justificado, puesto que sobre este tipo de industrias recaian principalmente las compras estatales, a través de los programas de obras públicas, principal partida de gasto en la inversión. No debe extrañar que un 10 por 100 de la variación de la producción en aquellas industrias venga determinado por la inversión pública (cuadro 8 ).

\section{GRAFICO 6}

Respuesta del IPIB a una innovación en el gasto público

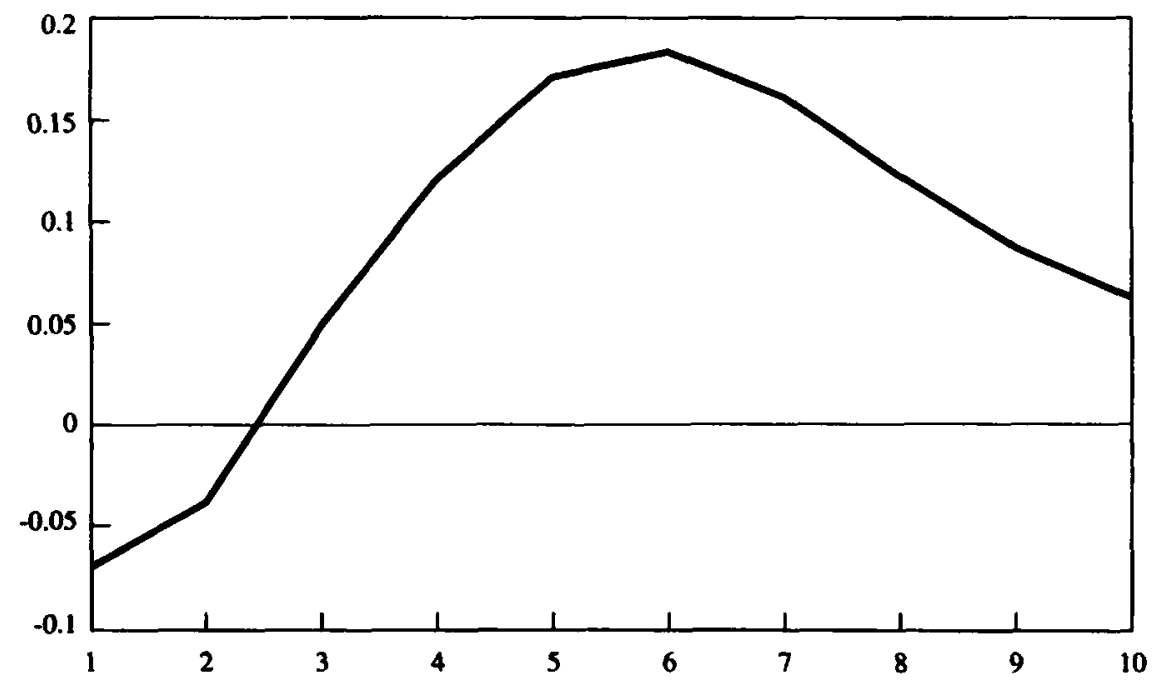

FuENTE: Véase texto.

IV

Durante la Restauración, la economia española contaba con escasos elementos que pudieran dinamizar la demanda interna. Los incrementos de productividad en el sector agrario eran muy limitados y la protección a la agricultura cerealística obstaculizaba el crecimiento de la agricultura de exportación mediterránea. El sector exterior no generó, tampoco, una demanda suficiente para sostener el crecimiento industrial, puesto que el proteccionismo obstaculizó la competitividad de la economia española. Solamente los sectores ciuda- 
danos en crecimiento sostenian los procesos de renovación del tejido industrial ${ }^{30}$, que, aunque limitada, provocó el crecimiento de nuevos sectores productivos como la agroalimentaria, la papelera y editorial, el juguete, el mueble y una extensa gama de bienes producidos por la metalurgia de transformación ${ }^{31}$.

\section{GRAFICO 7}

Respuesta del IPIB a innovaciones en el consumo y la inversión pública

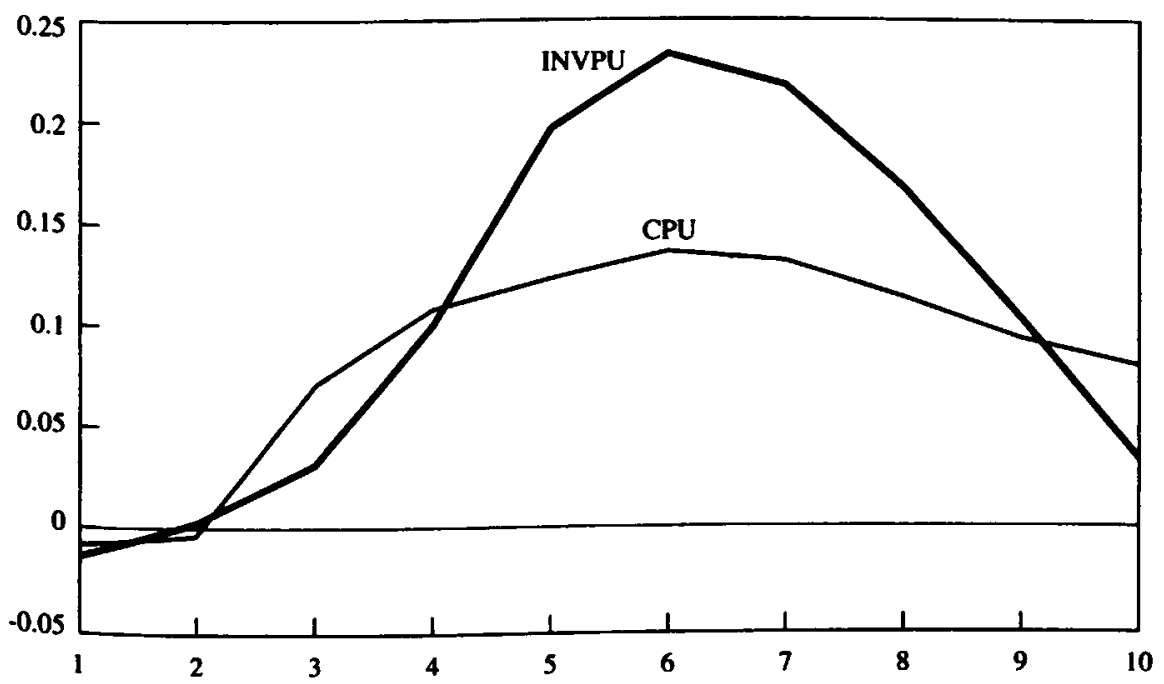

Fuente: Véase texto.

Dentro de ese marco, durante los años finales del siglo XIX la industria española ejerció una presión constante sobre el Estado para que éste complementara la demanda interna y dinamizara, en la medida de sus posibilidades, la producción industrial. A pesar de que las compras fueran pequeñas sobre el total del producto nacional, su importancia no era desdeñable en comparación

${ }^{30}$ Las anteriores consideraciones recogen algunas de las conclusiones a las que llegó el Seminario de Historia Económica de la Universidad de Valencia, y forman parte del proyecto de investigación financiado por la Dirección General de Investigación Cientifica y Tecnológica que con el titulo La industrialización española en su perspectiva bistórica están realizando Jordi Palafox, Concha Betrán, Enrique Morella y Daniel Tirado, además del autor.

"Maluquer (1987), pp. 77-78. 
con el producto industrial y alcanzaría valores notables respecto al producto de algunos sectores. La industria privada tenia en él un demandante de importante magnitud, al que intentó atraerse desde principios de la Restauración. Lo cual, dado el régimen político que imperaba, no iba a resultarle demasiado difícil.

\section{CUADRO 8}

Porcentaje de descomposición de la varianza, tres, seis y diez años adelante, en un sistema donde las variables son XM, INVPUB, INVPR, CPU, CPR e IPIB

\begin{tabular}{|c|c|c|c|c|c|c|c|}
\hline \multirow{2}{*}{$\begin{array}{l}\text { Innouación } \\
\text { de la variable }\end{array}$} & \multicolumn{7}{|c|}{ Varianze del error de } \\
\hline & & $X M$ & INVPUB & $I N V P R$ & $C P U$ & $C P R$ & IPIB \\
\hline \multirow[t]{3}{*}{$\mathrm{XM}$} & 3 & 69,8 & 26,2 & 23,0 & 21,1 & 11,7 & 0,2 \\
\hline & 6 & 61,8 & 24,3 & 23,9 & 20,0 & 16,7 & 7,7 \\
\hline & 10 & 55,3 & 29,0 & 23,8 & 29,6 & 20,3 & 8,6 \\
\hline \multirow[t]{3}{*}{ INVPUB } & 3 & 7,7 & 58,8 & 11,1 & 20,8 & 11,6 & 0,2 \\
\hline & 6 & 7,7 & 54,3 & 10,0 & 27,4 & 14,8 & 8,1 \\
\hline & 10 & 15,7 & 46,1 & 9,5 & 24,1 & 13,8 & 11,8 \\
\hline \multirow[t]{3}{*}{ INVPR } & 3 & 9,8 & 4,2 & 54,4 & 5,8 & 12,7 & 17,8 \\
\hline & 6 & 8,3 & 6,8 & 48,4 & 6,4 & 10,9 & 22,0 \\
\hline & 10 & 8,9 & 5,3 & 36,7 & 4,7 & 8,3 & 23,7 \\
\hline \multirow[t]{3}{*}{ CPU } & 3 & 2,1 & 4,9 & 4,9 & 38,3 & 5,7 & 0,6 \\
\hline & 6 & 2,1 & 4,4 & 7,5 & 27,7 & 8,9 & 3,9 \\
\hline & 10 & 2,7 & 3,3 & 6,9 & 17,1 & 7,9 & 5,9 \\
\hline \multirow[t]{3}{*}{ CPR } & 3 & 2,4 & 0,2 & 6,2 & 0,6 & 54,8 & 2,1 \\
\hline & 6 & 3,6 & 1,8 & 6,5 & 1,4 & 40,3 & 1,7 \\
\hline & 10 & 3,2 & 1,6 & 5,0 & 1,5 & 30,9 & 2,3 \\
\hline \multirow[t]{3}{*}{ IPIB } & 3 & 7,9 & 5,3 & 0,3 & 13,4 & 3,5 & 79,1 \\
\hline & 6 & 16,2 & 8,1 & 3,6 & 17,0 & 8,4 & 56,6 \\
\hline & 10 & 13,8 & 14,5 & 18,0 & 23,0 & 18,8 & 47,6 \\
\hline
\end{tabular}

De esta forma, las diferentes normas de protección a la industria encontraron una favorable acogida entre los productores. No solamente porque iban a permitirles mantener sus beneficios al amparo del manto protector del Estado, sino también porque a su sombra podían iniciar, con menor riesgo, procesos 
de expansión productiva y de renovación tecnológica. Como iba a ser el caso de la renovación de los métodos de producción de la industria siderúrgica, a raiz de las leyes de la escuadra, como la introducción del proceso Siemens Martín en las fábricas de La Felguera y Alios Homos de Bilbao en 1887 y 1890, respectivamente, a raiz de la demanda de acero, en sustitución del hierro, por los astilleros del Estado ${ }^{32}$. O como ocurrió con la transferencia de tecnologia y la mejora de capital humano que supuso la ley de la Escuadra de 1908, que dio lugar a la creación de la Sociedad Española de Construcción Naval ${ }^{33}$.

También la reserva del mercado para los suministradores del sector público puesta en funcionamiento a partir de 1908 contribuyó al crecimiento y renovación industrial. Asi lo hacía notar la Sociedad Española de Construcciones Metálicas ante la Comisión Protectora de la Producción Nacional 34. De la misma forma, el crecimiento de la industria del cemento Portland fue favorecida por la mejora de la infraestructura pública, especialmente por la construcción de pantanos y la ampliación y modernización de puertos ${ }^{35}$.

Todos estos testimonios y los resultados de la estimación presentada cuestionan la opinión de que la actividad estatal, y especialmente el gasto público, tuvo una importancia reducida en la evolución de la economia durante la Restauración ${ }^{36}$. De acuerdo con la evidencia que se ha aportado en este trabajo, no puede afirmarse que el gasto público no contribuyera con su demanda, a través de los efectos directos e indirectos generados, al crecimiento de la producción, total e industrial. Los resultados expuestos demuestran que la política fiscal durante la Restauración debe considerarse un elemento importante en la evolución de la producción nacional. La política de gasto del Estado (en el sentido en el que se considera en el modelo: un cambio no anticipado en el gasto) provocaba efectos expansivo sobre el GNB, básicamente debidos al consumo público, mientras la inversión muestra una influencia menor, explicando entre ambos un 10 por 100 de la variación del producto nacional. La influencia sobre la producción industrial es aún mayor: una cuarta parte de su

${ }^{32}$ Alzola y Minondo (1894), pp 179-180.

${ }^{33}$ Trebilcock (1973), pp. 260-262.

34 Archivo general de la Administración del Estado, Reciamación de la Sociedad Española de Construcciones Metálicas ante la Comisión Protectora de la Producción Nacional, 1 de agosto de 1908. Fondo del Archivo de Presidencia del Gobierno, caja 477.

3s Comisión Protectora de la Producción Nacional (1917) y Gómez Mendoza (1985).

36 Véase en la nota IV de Palafox (1991) una aplicación de la metodologia aqui utilizada para el periodo 1900-1935. En ella se demuestra que los resultados aqui obtenidos no son excepcionales, puesto que cuando se incorporan los años de la Dictadura de Primo de Rivera y la Segun. da República los efectos del gasto püblico son más intensos que para los años de la Resturación únicamente. 
variación está determinada por la evolución de las variables públicas, principalmente por los cambios en la inversión.

La politica de gasto público tuvo efectos expansivos sobre el producto nacional y, especialmente, sobre la industria. Estos se complementaron con el fomento a la innovación en algunos sectores industriales. Coexistiendo con ellos, ya son conocidas las políticas de restricción de la competencia, interior y exterior, llevadas a cabo. La actuación estatal se muestra, por tanto, con una mayor complejidad de la que se ha venido suponiendo hasta este momento.

\section{APENDICE A DESCRIPCION DE LOS DATOS}

Todos los datos hacen referencia a series anuales para el período 1874 1923. La mayoría de las variables estaban ya calculadas en el formato de números indices y a precios constantes. Cuando esto no ocurría, han sido transformadas para mantener la homogeneidad. Las series básicas eran consumo privado, consumo público, inversión y exportaciones netas. La descomposición de la inversión en pública y privada era también presentada en Carreras (1985). La descomposición del consumo se ha realizado calculando el porcentaje que suponia sobre el mismo cada una de sus componentes e imputando, a partir de éste, el porcentaje que suponian sobre el GNB. Las variables utilizadas han sido las siguientes:

CPR: Consumo Privado.

INVPR: Formación Bruta de Capital fijo del sector privado.

$\mathrm{XM}$ : Exportaciones netas.

SUSA: Sueldos y Salarios.

BISE: Compras de bienes y servicios.

CPU: Consumo Público.

CPU = SUSA + BISE

INVPUB: Formación Bruta de Capital fijo del sector público.

GPUB: Gasto Público.

GPUB $=$ CPU + INVPUB

GNB: Gasto Nacional Bruto.

IPIES: Indice de la producción industrial española.

IPIB: Indice de la producción de industrias básicas. 
Las definiciones de todas las variables son las ofrecidas por la Contabilidad Nacional. Los datos han sido obtenidos de las siguientes fuentes: Consumo, Inversión, Exportaciones Netas y Gasto Nacional Bruto: Carreras, Albert (1985); Compras de Bienes y Servicios y Sueldos y Salarios, Comin, F. (1985); Indice de la Producción Industrial española, Carreras, A. (1984); Indice de la Producción de las Industrias Básicas, Carreras, A. (1981).

\section{BIBLIOGRAFIA}

ALCAIDE, Julio (1976): «Una revisión urgente de la serie de renta nacional española en el siglo XX», en Instituto DE Estudios Fiscales (1976): Datos básicos para la bistoria financiera de España, 1850-1975, Madrid.

AlzOLA Y MINONDO, Benito de (1894): Las primas a la contrucción naval y a la navegación. Datos para una ley sobre la materia, Bilbao.

Ballabriga, Fernando (1992): «Instrumentación de la metodologia VAR*, Cuadernos Económicos del ICE, 48, pp. 85-104.

CAPIE, F. H.; Mills, T. C.; WoOD, G. E. (1991): \&Money, interest Rate and the Great Depression: Britain 1870 to 1913w, en Foreman PeCK, James (ed.): New perspectives on the Late Victorian economy. Essays in Quantitative Economic History 1860-1914, Cambridge, Cambridge U. P.

Carreras, Albert (1981): «Un indice de la producción de las industrias básicas, España 1861-1975w, Jomadas de Estadistica Española, Madrid, INE, t. III, pp. 127.139.

- (1984): «La producción industrial española, 1842-1941: Construcción de un indice anualw, Revista de Historia Económica, núm. 1, pp. 127-157.

- (1985): «Gasto Nacional Bruto y Formación de Capital en España», en MartiN Acena, P., y Prados de LA Escosura, L. (eds.) (1985): La Nueva Historia Económica en España, Madrid, Tecnos.

- (1988): «La industrialización española en el marco de la Historia Económica europea: ritmos y caracteres comparados», en GaRCIA Delgado, José Luis (director): España. Economia, Madrid, Espasa-Calpe.

Comin, Francisco (1985): Fuentes cuantitativas para el estudio del sector público en España, 1801-1980, Madrid, Instituto de Estudios Fiscales, Monografía núm 40.

- (1988): Hacienda y Economía en la España contemporánea (1800-1936), Madrid, Instituto de Estudios Fiscales.

Comision Protectora de la Produccion Nacional (1917): Ponencia sobre el Cemento Portland. Vocal Ponente, D. Severo Gómez Núñez, Madrid.

CRATFS, N. C. R. (1981): «The eighteenth century: a surveyw, en Floud, R, y McClos. KEY, D. (editores): The Economic History of Britain since 1870, Cambridge, Cambridge U.P.

Darnell, Adrian C., y Evans, J. Lynne (1990): The Limits of Econometrics, Londres, Edward Elgar, 1990.

DOAN, Thomas A. (1988): User's Manual, RATS, Versión 3.00. 
Fralle, Pedro (1985a): «El Pais Vasco y el mercado mundial, 1900-1930», en SanchezAlbornoz, N. (comp.): La modernización económica de España, 1830-1930, Madrid, Alianza.

(1985b): «El fracaso de la revolución Industrial en España: un modelo cerrado de industrialización», en Información Comencial Española, DCXXIII, pp. 97-104.

GarCla MILA, Teresa (1987): Government purcbases and real output: an empirical analysis and equilibrium model whit public capital Documents de discussió, w. p. 93.88, Institut d'Analisi Econòmica CSIC. Departament d'Economia i Historia Econòmica. Universitat Autònoma de Barcelona.

Gomez Mendoza, Antonio (1985): «La formación de un cartel en el primer tercio del siglo xx: la industria del Cemento Portland», Revista de Historia Económica.

- (1991): «Depresión agrícola y renovación industrial (1876-1898)», en GARCIA DeLGADO, J. Luis (editor): España entre dos siglos (1875-1931). Continuidad y cambio, Madrid, Siglo XXI.

HANSEN, Bent (1969): Fiscal Policy in Seven Countries, 1955-1965, O.E.C.D.

KEYNES, John Maynard (1936): The General Theory of Employment, Interest and Money, New York, Harcourt, Brace and Company.

LEAMER, E. E. (1985): «Vector autoregressions for causal inference?», Carmegie-Rochester Conference Series on Public Policy, 22, pp. 255-304.

LuCAs, Robert E., Jr. (1976): «Econometric Policy Evaluation: A Critique», en BrunNER, Karl, y Meltzer, Allan (editores): The Phillips Curve and Labor Markets, CarnegieRochester Conference Series on Public Policy, vol. 1, Amsterdam, North Holland.

MaluQuer Jordi (1987): «De la crisis colonial a la guerra europea. Veinte años de la economia españolaw, en Nadal, J.; Carreras, A., y Sudria, C. (comp.) (1987): La economia española en el siglo xx. Una perspectiva bistórica, Barcelona, Ariel.

Martin ACENa, Pablo, y Comin, Francisco (1984): «La politica monetaria y fiscal durante la Dictadura y la Segunda República», Papeles de Economía Española, núm. 20, pp. 236-261.

Martin Acena, Pablo, y Garcin Santos, Nieves (1990): «El comportamiento del gasto público en España durante la segunda república, 1931-1935m, Revista de Historia Económica, año VIII, núm 2, pp. 397-415.

Munoz, Juan; Roldan, Santiago, y Serrano, Angel (1978): «La involución nacionalista la vertebración del capitalismo español», Cuademos Económicos del ICE, núm. 5 , pp. 13-203.

NADAL, Jordi (1975): El fracaso de la revolución Industrial en Esparia, 1874-1913, Ed. Ariel, Barcelona.

Palafox, Jordi (1991): Atraso económico y democracia. La Segunda República y la economia española, Barcelona, Crítica.

Pryor, Zora: «Czechoslovak Fiscal Policies in the Great Depression», The Economic History Review, 1979, núm 3.

SArgent, Thomas J. (1979): Macroeconomic Theory, New York, Academic Press.

SARgent, Thomas J., y Wallace, Neil (1976): «Rational Expectations and the Theory of Economic Policyw, Joumal of Monetary Economics, vol. 2, (abril), pp. 169-183.

Sims, Christopher (1980): «Macroeconomic and reality», Econometrica, vol. 48, núm. 1, pp. 1.48.

(1982): «Policy Analysis with Econometric Models», Brookings Papers on Economic Activity, vol. 1, pp. 107-164. 
- (1992): «Macroeconometría VAR: una actualización», Cuademos Económicos del ICE, 48, pp. 63-84.

TEDDE, Pedro (1981): «El gasto público en España (1875-1906). Un análisis comparativo con las economias europeas», Hacienda Pública Española, núm. 69, pp. 236-266.

Tena, Antonio (1990): *Comercio Exterior», en CarReras, Albert (coord.): Estadísticas bistóricas de España, siglos XIX-XX, Madrid, Fundación Banco Exterior.

TREBILCOCK, Clive (1973): «British Armaments and European Industrialization, 1890 . 1914», Economic History Review, num. 2, pp. 254-272. 